\title{
BMJ Global Health Redressing the impact of COVID-19 on medical education in Africa: the need for collective action
}

\author{
Edmund Ndudi Ossai, ${ }^{1}$ Osondu Ogbuoji ${ }^{2}$
}

To cite: Ossai EN, Ogbuoji 0. Redressing the impact of COVID-19 on medical education in Africa: the need for collective action. BMJ Global Health 2021;6:e005067. doi:10.1136/ bmjgh-2021-005067

Handling editor Seye Abimbola

ENO and 00 contributed equally.

Received 19 January 2021 Revised 1 February 2021

Accepted 3 February 2021

A Check for updates

(c) Author(s) (or their employer(s)) 2021. Re-use permitted under CC BY-NC. No commercial re-use. See rights and permissions. Published by BMJ.

${ }^{1}$ Department of Community Medicine, College of Health Sciences, Ebonyi State University, Abakaliki, Ebonyi, Nigeria

${ }^{2}$ Center for Policy Impact in Public Health, Duke University, Durham, North Carolina, USA

Correspondence to Dr Edmund Ndudi Ossai; ossai_2@yahoo.co.uk

\section{INTRODUCTION}

The ongoing COVID-19 pandemic is harming medical education in Africa. This effect will likely grow as the pandemic evolves, and in some countries, become long lasting. However, while policy-makers have focused their attention on mitigating the impact of COVID-19 on the more visible parts of the health system (eg, service delivery and health finance), little attention has been given to the less visible but essential function of medical education. Africa bears $27 \%$ of the global burden of disease, yet has only $3.5 \%$ of the global health workforce and only $1.7 \%$ of the world's physicians. ${ }^{1}$ This situation will worsen due to the COVID-19 pandemic and the varied country responses. Currently, 24 countries in sub-Saharan Africa have only one medical school, while 11 countries have no medical school. ${ }^{2}$ Furthermore, the high total cost of medical education in the region, which ranges from US $\$ 18870$ in Uganda to US\$40383 in South Africa, ${ }^{3}$ and limited government support provided to students, place significant financial burdens on families and households.

With the onset of the COVID-19 pandemic, schools of medicine, nursing, and allied health training across Africa face challenges due to partial or total disruptions to their academic calendars. While some schools had complete shutdowns, others made adjustments, such as adopting remote learning methods. Nevertheless, these disruptions will have short-term, medium-term and long-term impacts on the number and quality of health workers trained on the continent, which will affect Africa's ability to achieve universal health coverage by 2030 .

In this paper, we discuss the impact of COVID-19 on medical education in Africa and assess policy-makers' options for mitigating these negative consequences. Current forecasts suggest that the pandemic could halt two decades of sustained economic growth in Africa, thus creating the region's first recession in 25 years. Such a recession will have far-reaching effects
Summary box

COVID-19 is having a negative impact on medical education in Africa.

- The impact of COVID-19 on Africa is enormous as the continent is expected to experience its first recession in 25 years.

The budget cuts from donor countries will affect access to research funds in the continent.

- There is the possibility of COVID-19 related brain drain which will worsen the poor human resource for health in the region with devastating effects on population health.

- Practical mitigation efforts such as long-term planning, protecting budgets and introducing e-learning and telehealth should be prioritised.

- African countries will not be able to provide the resources for the enormous investments needed for medical education at this period

- There is the need to replicate successful initiatives such as Medical Education Partnership Initiative, which helped foster South-to-South and South-to-North partnerships in medical education and research in Africa.

on medical education. Therefore, responding to the impact of COVID-19 on medical education will require collective action for (1) early identification of the problem and (2) out-ofthe-box thinking to design innovative, feasible, contextually appropriate and affordable solutions. In our discussion, we use the term medical education in an inclusive way, to describe both preservice and in-service training for all types of health workers regardless of professional affiliation. This includes physicians, nursing and allied health workers.

\section{COVID-19 CHALLENGES}

\section{Effect of COVID-19 on students' medical education}

COVID-19 has disrupted both in-class lectures and clinical training of medical, nursing and other allied health students in Africa. ${ }^{4}$ The lack of adequate personal protective equipment (PPEs) created unsafe environments for health workers 
and students across the continent. For example, in Nigeria, the National Association of Resident Doctors embarked on a national strike to protest the lack of PPEs in teaching and other hospitals during the COVID-19 pandemic. $^{5}$ In response to these shortages, the WHO supplied PPEs to several African countries, including Ethiopia, Gambia, Mauritania and Kenya.

Students also face challenges created by lockdowns. Between March and July 2020, education authorities in 44 out of 54 countries in Africa issued mandates to temporarily close all universities, including medical schools. ${ }^{6}$ These partial or total lockdowns have disrupted in-person didactic and clinical training. They have also resulted in cancellation or delays in academic and professional medical exams-final year medical students in Egypt requested the postponement of their examinations for fear of being infected with COVID19. These delays have extended graduation times and caused delays in commencing postgraduate medical training. These delays will also disproportionately affect female medical students who may face cultural pressures to drop-out or students from low-income families who find it difficult to cope with the extended stay in school. Furthermore, there is evidence that lockdowns are affecting the mental health of the students. A recent global survey revealed that $83 \%$ of young people believe that the COVID-19 pandemic, school closures and restricted social connections worsened preexisting mental health conditions. ${ }^{7}$

Some training institutions have adopted remote learning approaches such as e-learning and telemedicine, to mitigate the lockdowns' effect. However, the response has not been uniform. Only $38.5 \%$ of students in Africa's higher institutions had access to e-learning programmes during the pandemic, with the West African subregion having the least access. ${ }^{8}$ Expanding access to these technology-based solutions will further strengthen Africa's capacity for better medical education. ${ }^{9}$ However, the weak physical infrastructure for effective medical education in sub-Saharan Africa must be addressed. ${ }^{2}$

\section{Effect of COVID-19 on medical educators-teaching and research faculty}

Teaching and research faculty at medical training institutions in Africa also face a myriad of challenges from COVID-19. The pandemic's economic effects will jeopardise faculty members' reliance on the government for research funding and payment of salaries. Recent estimates from the International Monetary Fund predict that all countries in Africa will face economic contractions. At the same time, the continent as a whole will experience its first recession in 25 years. As a result, many countries have enacted emergency measures that include additional debt, budget cuts and reallocation of funds from other sectors. $^{10}$

The reduction in overall research funds is worsened by the increasing reallocation of existing research funds towards COVID-19. As more donors reprogram funds away from other research areas towards COVID-19, the diversity of research topics addressed will reduce, which will exacerbate the existing shortage of faculty in basic and clinical sciences in medical schools in Africa. ${ }^{2}$ Since most medical schools in sub-Saharan Africa receive grants from the government, decreased government spending may lead to salary cuts for medical educators. Thus, with worsening service conditions, medical educators (mostly nurses and physicians) may decide to move to highincome countries to search for better career opportunities. For instance, at the peak of the pandemic response in Nigeria, 58 Nigerian-trained physicians made headlines by leaving for the UK. ${ }^{11}$ This was in response to the new UK Health and Care Visa policy that makes it easier for healthcare professionals to migrate to the UK. The USA and other Western countries including Canada and Germany have also issued similar directives. These calls may evoke a mass migration of healthcare professionals from Africa to the developed economies, thus worsening the region's situation.

Donor budget cuts will also affect access to research funds in the continent. For example, based on the expected fall in government overseas aid spending, research institutions in the UK are preparing for significant cuts to flagship grant schemes, including the $£ 1.5$ billion Global Challenges Research Fund and the $£ 735$ million Newton Fund financed through the UK's aid budget. The cuts are due to the expected fall in overseas aid spending due to the impact of COVID-19. Similarly, the principal research agency in South Africa, the National Research Foundation, received 10\% less from the government due to the COVID-19 pandemic. ${ }^{12}$

\section{Effect of COVID-19 on schools of medicine, nursing and allied health services}

Institutions involved in medical education expect to face cash-flow challenges as a result of COVID-19. The pandemic's adverse economic impact will affect the government, households and development partners' ability to fund medical education in Africa. ${ }^{13}$ Government-owned universities expect decreased revenues from budget cuts to the ministries of education and health, while private universities will lose revenue from school fees. Teaching hospitals are experiencing decreased revenues due to a decrease in patients seeking care due to fears of contracting COVID19. This trend will negatively impact medical schools in several ways. First, the constant flow of patients seeking care at teaching hospitals creates teaching opportunities for medical students. Second, teaching hospitals partly subsidise medical-school budgets, and medical instructors supplement their income by providing patient care in teaching hospitals. Third, medical schools and teaching hospitals support multiple research collaborations, with the medical school providing the research capacity to study problems observed in patients visiting the hospital. Therefore, any decrease in patient volume will negatively impact medical education and research provided through collaborations between the medical school and teaching hospitals. Medical schools also face future challenges in their pipeline. The interruptions in 
Table 1 Effect of COVID-19 on medical education in Africa

\section{Medical education} component/stakeholder

Students and health workers in training

Medical educators - teaching and research faculty

\section{Effect of COVID-19}

Closure of universities and health worke training institutions.

- Delays and cancellation of examinations.

- Delays in graduation.

Increased mental health stress.

\section{Selected country examples}

- The President of Republic of Uganda announced the temporary closure of all educational institutions in the country including the medical schools beginning on the 20 March 2020.

- The Federal Government of Nigeria announced the closure of all tertiary institutions including the medical schools on the 19 March $2020 .^{26}$

- The Ethiopian Government announced the closure of all schools in the country by March 2020.

- In the second wave of COVID-19, several universities in Sudan announced the suspension of classes. ${ }^{27}$

- The West African College of Physicians postponed the April/May 2020 postgraduate medical examinations. ${ }^{28}$

- Final year medical students in Egypt requested for the postponement of their examinations for fear of being infected with COVID-19. ${ }^{29}$

- Since the closure of universities in Nigeria on 19 March 2020 , there has been no academic activities in all public medical schools in Nigeria till the end of 2020 hence no medical graduates from any of the schools.

- In a survey of young people (including students) round the globe, $83 \%$ of respondents reported that the pandemic worsened pre-existing mental health conditions. ${ }^{7}$

- Decreased access to research funds from internal and external sources.

- Budget cuts leading to delayed salaries, and job losses.

- Increased brain drain as African health workers move to high income countries.
Schools of medicine, nursing and allied health services
- Shortage of personal protective equipment (PPEs).

- Decreased funding to medical schools.

- Reduced number of patients seeking care from teaching hospitals

- Decreased revenue from patient care.

- Reduced research opportunities, collaborations and partnerships.

- Decrease in research outputs, for example, publications, seminars.
- Budget cuts in South Africa have compromised the ability of higher education and research systems to meet postgraduate funding targets. ${ }^{30}$

- In Nigeria, a State government requested of university teachers including medical educators to sacrifice $20 \%$ of their salaries as a result of COVID-19. ${ }^{31}$

- Another State in Nigeria did not pay its university teachers including medical educators for the first 6 months into the pandemic. $^{32}$

- In Rwanda, some private sector universities suspended academic and administrative staff and reduced the salaries of others. ${ }^{33}$

- In Zimbabwe, medical doctors and other health workers held a protest over the decision by the government to reduce their wages in response to COVID-19. ${ }^{34}$

- Fifty-eight medical doctors from Nigeria emigrated as a group to the United Kingdom at the peak of the pandemic. ${ }^{11}$

- Ethiopia, Gambia, Mauritania and Kenya faced severe shortages of PPE supplies and so received supplies from the $\mathrm{WHO}^{35}$

- In the revised 2020 budget, Nigeria announced budgetary cuts for education and health as a result of COVID-19 pandemic. $^{36}$

- In South Africa, the National Research Foundation got a $19 \%$ reduction in government allocation for research grants as a result of the COVID-19 pandemic. ${ }^{30}$

- In Nigeria, several public and private health facilities turned away patients during the COVID-19 pandemic.

- In Zimbabwe, clinics turned away patients with malaria for fear they could be infected with COVID-19. ${ }^{37}$

- Authors from developing countries were involved in only $11 \%$ of early articles published on COVID-19 as against $15 \%$ participation before the pandemic. ${ }^{14}$

- The United States Bureau of Educational and Cultural Affairs suspended all exchange programmes that involve travelling to and from the USA because of COVID-19 pandemic. $^{38}$ 
Table 1 Continued

\begin{tabular}{|c|c|c|}
\hline $\begin{array}{l}\text { Medical education } \\
\text { component/stakeholder }\end{array}$ & Effect of COVID-19 & Selected country examples \\
\hline Society & $\begin{array}{l}\text { Medical students may drop out of school } \\
\text { due to COVID-19 delays. } \\
\text { Students in training and drop outs may } \\
\text { practice as quacks in the community. } \\
\text { Migration of healthcare professionals to } \\
\text { developed economies. } \\
\text { Abuse of health work force } \\
\text { Health workers being infected with } \\
\text { COVID-19 } \\
\text { Death of health workers from COVID-19 }\end{array}$ & $\begin{array}{l}\text { Arab News Network reported on } 16 \text { May } 2020 \text { that a total } \\
\text { of } 8600 \text { medical doctors from Egypt have been accepted } \\
\text { in the USA based on a call for application from medical } \\
\text { professionals especially those working on COVID-19.39 } \\
\text { Health workers in Malawi complained of insults, stigma } \\
\text { and discrimination because of their involvement in the } \\
\text { fight against COVID- } 19 .^{40} \\
\text { On } 23 \text { July } 2020 \text {, the WHO announced that more than } \\
10000 \text { health workers in } 40 \text { African countries have been } \\
\text { infected with COVID-19. } \\
\text { The Nigerian Medical Association announced on } 26 \\
\text { December } 2020 \text { that } 20 \text { medical doctors in Nigeria died } \\
\text { from COVID-19 infection in } 1 \text { week. }{ }^{42}\end{array}$ \\
\hline
\end{tabular}

their academic calendar will affect their ability to graduate new health workers, while interruptions in primary and secondary schools' academic calendars will reduce new enrolments.

COVID-19 has also exposed the weak infrastructure for rapid research and updates in many of Africa's medical schools. For example, a look at early research articles published on COVID-19 revealed a disproportionately low representation of researchers from developing countries. Authors from developing countries were involved in only $11 \%$ of early articles published on COVID-19 against $15 \%$ participation before the pandemic. ${ }^{14}$ The pace of research and development for COVID-19 is fast, and medical schools in Africa have not demonstrated the ability to keep up with the pace. These schools also have limited access to academic journals, limiting their ability to review and domesticate new evidence rapidly. Furthermore, COVID-19 travel restrictions have affected North-South research partnerships and exchange programmes. For example, the United States Bureau of Educational and Cultural Affairs suspended all exchange programmes that involved travelling to and from the United States because of the COVID-19 pandemic. Many academic institutions in high-income countries have placed restrictions on the scope of their non-COVID-19 research collaborations in Africa.

\section{Long-term impact of on society}

In the long run, African communities will suffer health consequences if these COVID-19 effects on medical education are not addressed. The prolonged closure of training institutions will create incentives for students to drop-out or practice as quacks in their communities without completing their training. Since health worker activities are poorly regulated in many African countries, ${ }^{15}$ the result will be an increase in the number of quacks providing healthcare, leading to an increase in poor-quality care and amenable deaths on the continent. $^{16}$

Reallocation of funds towards COVID-19 will encourage internal brain drain (ie, switching of focus from other diseases towards COVID-19). Simultaneously, poor service conditions will cause external brain drain (ie, move to other countries in search of better opportunities). The net effect on society is a worsening of the health workforce capacity on the continent. Before COVID-19, African countries lost substantial medical education investments through the emigration of medical doctors and nurses to wealthier destination countries. ${ }^{3}$ This trend will worsen due to the pandemic if stakeholders do not adopt effective mitigating (see table 1 ).

\section{POLICY OPTIONS AND RECOMMENDATIONS}

The challenges created by COVID-19 are not insurmountable. Early implementation of common-sense solutions would enable African countries to capitalise on this opportunity to build better medical education systems. Policies that take the long-term view, include relevant stakeholders, are well coordinated and funded, are more likely to produce maximum impact. We propose that stakeholders pay attention to six potentially highimpact policy goals and action steps. These include (1) strengthening of health workforce planning processes, (2) protect and increase funding for medical education and research, (3) build infrastructure needed to support innovations in medical education and research, (4) expand e-learning and telehealth services, (5) strengthen capacity building initiatives that improve medical education and medical research, and (6) prioritise medical education and research in policy-making discussions across the continent. We describe each below and provide a summary with examples in table 2 .

1. Strengthen health workforce planning processes: effective planning for health workforce development and retainment is a foundational requirement for building a strong health workforce. In recognition of its importance, the WHO provides technical support to help countries develop, cost, implement, monitor and update health workforce plans. In the wake of COVID-19, these processes need to be strengthened 
Table 2 Exemplar policy options and actions

Policy goal
Strengthen health workforce
planning processes.

Protect and increase funding for medical education and research.

\section{Examples of policy options and actions}

- Develop costed national health workforce plans that include clear goals to build and retain an optimal mix of health workforce cadres.

- Update existing health workforce plans to reflect changing realities due to COVID-19 and other external shocks.

- Increase interministerial coordination for health workforce planning and development. For example, improve coordination between the ministry of education (trainers of the health workforce), the ministry of health (largest employers of health workforce) and the ministry of finance (provider of funding for health workforce training).

- Ensure there is a line item for medical education and research in government budgets. If line-item already exists, ensure that policy makers do not reallocate funds away from medical education and research in response to COVID-19 challenges.

- Create government-funded peer-reviewed research grants to encourage medical school faculty compete for sustainable research funds.

- Develop incentives to increase private investments in research conducted by medical school faculty, such as, public-private partnerships, cost-share grants, university endowments.

- Increase access to scholarships, financial aid, and loans for students and health workers in training.

- Increase official development assistance for medical education and research. Continental stakeholders such as the African Development Bank can play a leading role to complement resources from traditional donors.

Build infrastructure needed to support innovations in medical education and research.
- Expand access to reliable and affordable broadband internet for medical schools, their faculty, and their students.

- Increase access to and use of digital libraries by faculty, students and other staff of medical schools.

- Promote widespread use of secure, contextually appropriate, medical information systems for patient care, payments and reporting.

- Invest in the expansion of access to clinical simulation laboratories for medical school instruction.

- Foster development of institutional partnerships as a backbone infrastructure for collaboration and knowledge sharing.
Expand e-learning and telehealth services.
Update teaching curricula to include e-learning modules.

- Support faculty members to create high-quality e-learning course modules appropriate for the country context.

- Remove barriers that prevent students from getting academic credit for e-learning offerings from other institutions.

- Allow healthcare providers receive payments/remuneration for telehealth services performed.
Strengthen capacity building initiatives that improve medical education and medical research. and research in policy-making discussions across the continent.

Provide long-term, sustainable funding for the African Forum for Research and Education in Health (AFREhealth).

- Use domestic resources to build on the foundations laid by joint initiatives such as MEPI, NEPI, HEPI.

- Reactivate the African Medical Schools Association to foster institutional exchange of best practices for medical education development. Similar efforts should be developed for nursing and other allied health professions

- Create visibility on the role of medical education in ensuring that Africa meets its health-related goals in the AU Agenda 2063.

- Introduce medical education in Africa as a top agenda in high-level policy meetings such as the Africa Leadership Meeting, African Union general assembly or regional meetings.

- Advocate for high-level policy-making institutions on the continent to issue joint statements on need for medical education capacity building in Africa. Institutions such as the United Nations Economic Cooperation for Africa, the Africa Academy of Sciences, Africa Centers for Disease Control and Prevention, and the Africa Development Bank can play pivotal roles.

- Encourage convening of a special body/task force to brainstorm health workforce issues on the continent

HEPI, Health-Professional Education Partnership Initiative; MEPI, Medical Education Partnership Initiative; NEPI, Nursing Education Partners Initiative.

at the country level in order to reflect the new realities of COVID-19.

2. Protect and increase funding for medical education and research: adverse economic times make it more important to prioritise continued financing of medical education. ${ }^{17}$ This ensures a continuous stream of health workers to address the health challenges that typically increase with economic slumps. With COVID-19 effect on the economy, and the high probability of diversion of funds away from other health components, policy-makers should actively protect and increase allocations to funding of medical education, research and student scholarship. Policy options include creating and protecting line items for 
medical education in health systems budgets, creating incentives to encourage private sector participation in medical education funding, and expanding access to financial aid for students and health workers in training.

3. Build infrastructure needed to support innovations in medical education and research: innovations in medical education and research depend on the availability of a functioning physical infrastructure. ${ }^{19}$ Initiatives such as telehealth and e-learning would require policies to make broadband internet more accessible and affordable, while creation of digital libraries and clinical simulation laboratories will improve knowledge access and skills development, respectively. It has been postulated that prioritising the scale up of medical education is part of overall health system strengthening. ${ }^{20}$

4. Expand e-learning and telehealth services: another potentially high-impact intervention is to invest in remote teaching capabilities by expanding online medical education ${ }^{21}$ and telehealth within the continent. This expansion will strengthen the health system, improve medical education quality and enhance faculty effectiveness. ${ }^{22}$ It will also prevent future interruptions to academic calendars due to unexpected shocks like COVID-19 and facilitate early return to in-class and elearning, which will in-turn reduce drop-outs and mental health problems. It will also enable the students to exert greater control over their learning. ${ }^{23}$ Furthermore, it will create opportunities for improved patient care through telehealth. Policy options include allowing payments for telehealth to encourage service providers to expand access, supporting teaching faculty to develop e-learning modules, and allowing students access to e-learning options from multiple academic/ training institutions.

5. Strengthen capacity building initiatives that improve medical education and medical research: several important collaborative capacity building initiatives have been implemented in Africa. These range from the Human Heredity and Health in Africa Initiative, Medical Education Partnership Initiative (MEPI), Nursing Education Partners Initiative, and the African Association for Health Professions Education and Research. Together, these initiatives have spurred investments of over US\$300 million to improve medical education in Africa over the past decade and have strengthened medical education capacity in Africa. ${ }^{24}$ Box 1 describes some important initiatives. Similar initiatives should be pursued to build on the success of previous ones. However, domestic funding from individual African countries and agencies like the African Development Bank should be included to encourage sustainability. ${ }^{25}$ These new initiatives will create systems to encourage research funding, research network development, development of South-to-South and South-to-North partnerships for a post-COVID-19 future in subSaharan Africa.
Box 1 Medical education collaboratives

Human Heredity and Health in Africa Initiative A 10-year (2011-2021), US\$176 million project to build healthresearch capacity in Africa. ${ }^{43}$ It is jointly sponsored by US National Institutes of Health (NIH), the Wellcome Trust and the African Academy of Sciences. Although not directly targeted at medical education, the research capacity built through its 51 development projects has a direct influence on the quality of medical education on the continent.

\section{Medical Education Partnership Initiative (MEPI)}

A 5-year (2010-2015), US\$130 million programme to increase the number of medical graduates, the quality of medical education, and the retention of medical graduates in Africa ${ }^{44}$ It was jointly funded by the US Presidents Emergency Plan for AIDS Relief (PEPFAR) and NIH. MEPI funded 13 grants in 12 African countries and is largely considered a success. Funded interventions included increasing medical school enrolment, curricula revision and expanded use of clinical skills laboratories, faculty recruitment and development, and expansion of e-learning. It also generated additional funding from African governments. ${ }^{45}$

\section{Nursing Education Partnership Initiative (NEPI)}

A 5 year (2012-2016), US\$130 million programme to build nursing capacity in six African countries (Democratic Republic of Congo, Ethiopia, Lesotho, Malawi, South Africa and Zambia). ${ }^{46} 47$ The programme was jointly funded by PEPFAR, and the U.S. Department of Health and Human Services/Health Resources and Services Administration with support from host countries. Funded interventions included curricular reform, improving the quality of nursing education, expansion of clinical skills simulation labs, faculty development and institutional capacity building. NEPI is also considered a big success and has helped transform nurse-led HIV care in sub-Saharan Africa.

Health-Professional Education Partnership Initiative (HEPI) A \$22 million initiative funded by the NIH to build on the success of MEPI and NEPI in Africa. HEPI supports educational, research and partnership development programmes in eight African countries (Ethiopia, Kenya, Malawi, Mozambique, Tanzania, Uganda, Zambia and Zimbabwe). ${ }^{48}$

African Association for Health Professions Education and Research (AFREHealth)

A multidisciplinary network of African researchers working towards building health research capacity in Africa. The network was developed out of collaborations formed during MEPI and NEPI and is funded through a 5 year US $\$ 4$ million grant from the NIH to date. ${ }^{49} 50$

6. Prioritise medical-education and research in policymaking discussions across the continent: to ensure sustained funding and development of medical education in Africa, policy-makers must increase the visibility of medical education policies in policy-making circles on the continent. Institutions such as the United Nations Economic Cooperation for Africa, the Africa Academy of Sciences, Africa Centers for Disease Control and Prevention, and the Africa Development Bank can play pivotal roles. Examples of policies include (a) highlighting the importance of medical education in helping Africa meet its health-related sustainable development goals and Africa Agenda 2063, (b) including medical education in Africa as a top 
agenda in high-level policy meetings such as the Africa Leadership Meeting, African Union general assembly or regional meetings, (c) advocate for high-level policy-making institutions on the continent to issue joint statements on need for medical education capacity building in Africa, and (d) encourage convening of a special body/task force to brainstorm health workforce issues on the continent.

These recommendations are not new but are more important in light of the impact that COVID-19 has had on the medical education system in Africa. They should therefore be strongly considered and implemented where appropriate by different African countries. However, this list does not constitute an exhaustive list of policy options but rather examples of alternatives for consideration by policy-makers.

\section{CONCLUSION}

The negative impact of the COVID-19 pandemic on medical education continues to grow. If left unchecked, it could worsen the health workforce situation within the continent with devastating effects on population health. Practical mitigation efforts such as long-term planning, protecting budgets and introducing e-learning and telehealth, should be prioritised and funded by African governments immediately. Moreover, due to the effect of COVID-19 on the economies of African countries, it is less likely that Africa will be able to provide the resources for the enormous investments needed for medical education. Therefore, some countries will still require external support. Hence, there is a need to replicate successful initiatives such as MEPI, which helped foster Southto-South and South-to-North partnerships in medical education and research in Africa.

Contributors Both authors contributed equally.

Funding The authors have not declared a specific grant for this research from any funding agency in the public, commercial or not-for-profit sectors.

Competing interests None declared.

Patient consent for publication Not required.

Provenance and peer review Not commissioned; externally peer reviewed.

Data availability statement There are no data in this work.

Open access This is an open access article distributed in accordance with the Creative Commons Attribution Non Commercial (CC BY-NC 4.0) license, which permits others to distribute, remix, adapt, build upon this work non-commercially, and license their derivative works on different terms, provided the original work is properly cited, appropriate credit is given, any changes made indicated, and the use is non-commercial. See: http://creativecommons.org/licenses/by-nc/4.0/.

\section{REFERENCES}

1 World Health Organization. Working together for health, the world health report. Geneva: WHO, 2006.

2 Mullan F, Frehywot S, Omaswa F, et al. Medical schools in subSaharan Africa. Lancet 2011;377:1113-21.

3 Mills EJ, Kanters S, Hagopian A, et al. The financial cost of doctors emigrating from sub-Saharan Africa: human capital analysis. BMJ 2011;343:d7031.

4 Tamrat W, Teferra D. COVID-19 poses serious threat to higher education. University world news. Available: www. universityworldnews.com>post [Accessed 2 Sept 2020].
5 VOe News. COVID-19 pandemic. striking doctors in Nigeria demand COVID-19 PPE, hazard pay. Available: www.voanews.com>covid19-pandemic >striking-do [Accessed 2 Sept 2020].

6 UNESCO. School closures caused by coronavirus (Covid-19). Available: www.en.unesco.org>covid19>educationresponse [Accessed 2 Sept 2019].

7 YoungMinds. Coronavirus: impact on young people with mental health needs. Available: www.youngminds.org.uk/media/3708/ coronavirus-report_march2020.pdf [Accessed 3 Sept 2020].

8 Mawazo Institute. Survey Report: The impact of GOVID-19 on Africa's higher education system, 2020. Available: www. mawazoinstitute.org>our-publications [Accessed 10 Sept 2020].

9 Guze PA. Using technology to meet the challenges of medical education. In: Transactions of the American clinical and Climatological association. , 2015: 126, 260-70.

10 International Monetary Fund. Policy responses to COVID-19. Available: www.inf.org/en/Topics/imf-and-covid19/PolicyResponses-to-COVID-19 [Accessed 2 Sept 2020].

11 The Guardian. UK's new migration lures Nigerian doctors NigeriaThe. Available: www.guardian.ng $>$ news $>$ uks-new-migrationvisa=lures-mg [Accessed 6 Sept 2020].

12 ScienceMag. South Africa slashes science budget funds for giant radio. Available: www.sciencemag.org>news>2020/06>southafrica-s [Accessed 2 Sept 2020].

13 Al-Samarrai S, Maulshree G, Prival G. The impact of the COVID-19 pandemic on education financing. economic impact of COVID-19. Washington DC: World Bank, 2020.

14 Fry CV, Cai X, Zhang Y, et al. Consolidation in a crisis: patterns of international collaboration in early COVID-19 research. PLoS One 2020;15:e0236307.

15 Ndububa VI. Medical quackery in Nigeria; why the silence? Niger $J$ Med 2007;16:312-7.

16 Kruk ME, Gage AD, Joseph NT, et al. Mortality due to lowquality health systems in the universal health coverage era: a systematic analysis of amenable deaths in 137 countries. Lancet 2018;392:2203-12.

17 Walsh K. Medical education: the case for investment. Afr Health Sci 2014;14:472-4.

18 Walsh K. Medical education: return on investment. Ulster Med J 2015;84:111-2.

19 O'Doherty D, Dromey M, Lougheed J, et al. Barriers and solutions to online learning in medical education - an integrative review. BMC Med Educ 2018;18:130.

20 SMHS. The sub-Saharan African medical schools study data, observation and opportunity. Report brief. Available: https://smhs. gwu.edu/medicine/sites/medicine/files/125.pdf [Accessed 50 Dec 2020].

21 Choules AP. The use of elearning in medical education: a review of the current situation. Postgrad Med J 2007;83:212-6.

22 Frehywot S, Vovides Y, Talib Z, et al. E-Learning in medical education in resource constrained low- and middle-income countries. Hum Resour Health 2013;11:4.

23 Huynh R. The role of e-learning in medical education. Acad Med 2017:92:430.

24 Kristiansen C. Africa transforms its medical education with medical education partnership initiative. global health matters. Newsletter, 2012. Available: www.fic.nih.gov/News/GlobalHealthMatters/ september-october-2012/pages/mepi-africa [Accessed 26 Aug 2020].

25 Kasprowicz VO, Chopera D, Waddilove KD, et al. African-led health research and capacity building- is it working? BMC Public Health 2020;20:1104.

26 Ossai EN. Impact of COVID-19 on medical education and the challenges: how prepared is Nigeria? Pan Afr Med J 2020;37:45.

27 INHEA. Sudan- international network for higher education in Africa. Available: www.inhea.org >ahen>sudan [Accessed 6 Jan 2021].

28 DoctorsQuarters. Coronavirus: WACP postpones primary, part 1 , part 2. Available: www.doctorsquarters.com $>$ wacp-primary-part-1[Accessed 6 Sep 2020].

29 FanaMedia. Afraid of infection, medical students in Egypt want to. Available: www.al-fanamedia.org>2020/06>afraid-of-infection [Accessed 30 Jul 2020].

30 Unversity World News. Concern over cuts to higher education, science budgets. Available: www.universityworldnews.com>pos [Accessed 24 Aug 2020].

31 Tribune. Sacrifice 20\% of your salary, Umahi urges EBSU staff. Available: www.tribuneonlineng.com $>$ LatestNews[Accessed 1 Dec 2020].

32 Premium Times. Abia university staff protest non-payment of salaries. Available: ww.premiumtimesng.com>regional>ssoutheast $>4$ [Accessed 10 Dec 2020]. 
33 University World News. Private universities start suspending staff, cutting salaries. Available: www.universityworldnews.com>pos [Accessed 10 Aug 2020].

34 Anadolu Agency. Zimbabwe: healthcare workers walk out over wage cuts. Available: www.aa.com.tr>africa >zimbabwe-healthcareworkers [Accessed 11 Sep 2020].

35 World Health Organization. Shortage of personal protective equipment endangering. Available: www.who.int $>$ Newsroom $<$ Detail [Accessed 3 Sep 2020].

36 AllAfrica. Nigeria: revised Budget- anger over cuts in health. Available: www.allafrica.com>stories [Accessed 11 Sept 2020].

37 AllAfrica. Zimbabbwe: Mutoko clinics turn away malaria patients in fear. Available: www.allafrica.com>stories[Accessed 11 Sept 2020].

38 US Embassy. Temporary pause of international exchange programs due to. Available: www.ge.usembassy.gov>temporary-pause-ofinternational-e [Accessed 10 Aug 2020].

39 University World News. COVID-19 drives medical brain drain- is it all bad? Available: www.universityworldnews.com>post [Accessed 11 Sep 2020].

40 VOA News. Malawi health workers face stigma, discrimination over. Available: www.voanews.com>covid-pandemic >malawi-hea [Accessed 29 Aug 2020].

41 AFRO. Over 10,000 health workers in Africa infected with COVID-19. Available: www.afro.who.int>news>over010-000-health-worker [Accessed 29 Nov 2020].

42 Premium Times. COVID-19: 20 Nigerian doctors died in last one week-NMA. Available: www.premiumtimesng.com $>$ headlines $>43317$ [Accessed 7 Jan 2021].
43 H3Africa. Human Hereditary \& Health in Africa. Available: https:// h3africa.org/ [Accessed 24 Dec 2020].

44 Kilmarx $\mathrm{PH}$, Katz F, Razak $\mathrm{MH}$, et al. The medical education partnership initiative: strengthening human resources to end AIDS and improve health in Africa. Acad Med 2019;94:1704-13.

45 Glass RI, Katz F, Puderbaugh A, et al. What has the MEPI program taught us? Ann Glob Health 2018;84:4-6.

46 Middleton L, Howard AA, Dohrn J, et al. The nursing education partnership initiative (NEPI): innovations in nursing and midwifery education. Acad Med 2014;89:S24-8.

47 PEPFAR. The PEPFAR nursing education partnership initiative (NEPI) 2012-2016: transforming nursing and midwifery education in subSaharan Africa. Available: https://icap.columbia.edu/wp-content/ uploads/ICAP_GNCBP_NEPI_Report_2012-2016.pdf [Accessed 24 Dec 2020].

48 Fogarty International Center. Health-Professional education initiative (HEPI). Available: https://www.fic.nih.gov/Programs/Pages/healthprofessional-education-partnership-initiative-hepi.aspx [Accessed 24 Dec 2020].

49 Sewankambo NK, Donkor P. Linkage of the medical education partnership initiative (MEPI) and the nursing education partnership initiative (NEPI) to the African forum for research and education in health (AFREhealth). Ann Glob Health 2018;84:1-3.

50 Omaswa F, Kiguli-Malwadde E, Donkor P, et al. Medical education partnership initiative gives birth to AFREhealth. Lancet Glob Health 2017;5:e965-6. 